\title{
Effects of a multipronged beverage intervention on young children's beverage intake and weight: a cluster-randomized pilot study
}

\author{
Anna H Grummon ${ }^{1,2}$, Michael D Cabana ${ }^{3,4,5}$, Amelie A Hecht ${ }^{6}$, Abbey Alkon7, \\ Charles E McCulloch ${ }^{5}$, Claire D Brindis ${ }^{3,4,8}$ and Anisha I Patel ${ }^{9, *}$ \\ 'Department of Health Behavior, Gillings School of Global Public Health, University of North Carolina at Chapel Hill, \\ Chapel Hill, NC, USA: ${ }^{2}$ Carolina Population Center, University of North Carolina at Chapel Hill, Chapel Hill, NC, USA: \\ ${ }^{3}$ Department of Pediatrics, University of California San Francisco, San Francisco, CA, USA: ${ }^{4}$ Philip R. Lee Institute for \\ Health Policy Studies, University of California San Francisco, San Francisco, CA, USA: ${ }^{5}$ Department of Epidemiology \\ and Biostatistics, University of California San Francisco, San Francisco, CA, USA: ${ }^{6}$ Department of Health Policy and \\ Management, Johns Hopkins University, Baltimore, MD, USA: ${ }^{7}$ School of Nursing, Department of Family Health Care \\ Nursing, University of California San Francisco, San Francisco, CA, USA: ${ }^{8}$ Department of Obstetrics, Gynecology, and \\ Reproductive Sciences, University of California San Francisco, San Francisco, CA, USA: ${ }^{9}$ Department of Pediatrics, \\ Stanford University, 1265 Welch Road MSOB X240, Mailcode 5459, Stanford, CA 94305, USA
}

Submitted 24 October 2018: Final revision received 3 March 2019: Accepted 2 April 2019: First published online 15 July 2019

\begin{abstract}
Objective: To evaluate whether a multipronged pilot intervention promoting healthier beverage consumption improved at-home beverage consumption and weight status among young children.

Design: In this exploratory pilot study, we randomly assigned four childcare centres to a control (delayed-intervention) condition or a 12 -week intervention that promoted consumption of healthier beverages (water, unsweetened low- or non-fat milk) and discouraged consumption of less-healthy beverages (juice, sugar-sweetened beverages, high-fat or sweetened milk). The multipronged intervention was delivered via childcare centres; simultaneously targeted children, parents and childcare staff; and included environmental changes, policies and education. Outcomes were measured at baseline and immediately post-intervention and included children's ( $n$ 154) at-home beverage consumption (assessed via parental report) and overweight/obese status (assessed via objectively measured height and weight). We estimated intervention impact using difference-indifferences models controlling for children's demographics and classroom.

Setting: Two northern California cities, USA, 2013-2014.

Participants: Children aged $2-5$ years and their parents.

Results: Relative to control group children, intervention group children reduced their consumption of less-healthy beverages from baseline to follow-up by 5.9 ounces/d (95\% CI -11.2, -0.6) (-174.5 ml/d; $95 \%$ CI -331.2, -17.7) and increased their consumption of healthier beverages by 3.5 ounces/d (95\% CI $-2.6,9.5)(103.5 \mathrm{ml} / \mathrm{d}$; $95 \%$ CI -76.9, 280.9). Children's likelihood of being overweight decreased by 3 percentage points (pp) in the intervention group and increased by $3 \mathrm{pp}$ in the control group (difference-in-differences: -6 pp; $95 \%$ CI -15, 3).

Conclusions: Our exploratory pilot study suggests that interventions focused comprehensively on encouraging healthier beverage consumption could improve children's beverage intake and weight. Findings should be confirmed in longer, larger studies.
\end{abstract}

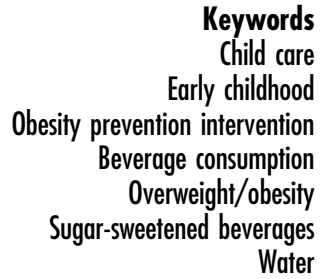

Keywords

Early childhood

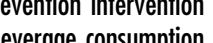

Overweight/obesity

Water
More than one in four US children aged $2-5$ years are overweight or obese ${ }^{(1)}$, increasing their risk for poor health outcomes and premature death in adulthood ${ }^{(2,3)}$. Children's beverage consumption habits are an important driver of childhood obesity. For example, consumption of sugarsweetened beverages (SSB) such as sodas, sports drinks and fruit-flavoured drinks increases risk of excess weight gain $^{(4-6)}$. Likewise, a recent meta-analysis found that 
consumption of $100 \%$ fruit juice is associated with a small amount of weight gain among children aged $1-6$ years ${ }^{(7)}$, and one study found that fruit juice consumption in early childhood is associated with higher SSB intake and higher BMI later in childhood $^{(8)}$. Conversely, consumption of healthier beverages, such as water, may help limit excess weight gain in children ${ }^{(9,10)}$.

Experts agree that 2- to 5-year-olds should drink low- or non-fat milk and plain water, consume no more than 118-177 ml (4-6 ounces) of 100\% fruit juice daily and limit their consumption of SSB (see online supplementary material, Supplemental Table S1) ${ }^{(11-13)}$. While debate remains over whether to encourage children to drink sweetened milk ${ }^{(14)}$, one expert panel advised against promoting sweetened milk $^{(11)}$, noting that its consumption is associated with increased energy intake ${ }^{(15)}$. Despite these guidelines, many children consume juice, SSB, and sweetened or high-fat milk ${ }^{(16-18)}$. On any given day, $45 \%$ of children aged $2-5$ years consume $100 \%$ fruit juice and $47 \%$ consume SSB, with average intake at $222 \mathrm{~kJ} / \mathrm{d}(53 \mathrm{kcal} / \mathrm{d})$ for juice and more than $251 \mathrm{~kJ} / \mathrm{d}(60 \mathrm{kcal} / \mathrm{d})$ for $\mathrm{SSB}^{(16)}$. Given the limited progress in reversing the obesity epidemic among young children $^{(1)}$, new efforts are needed to improve young children's beverage intake and limit their excess weight gain ${ }^{(16,18)}$.

Childcare facilities are an important setting for reaching young children and their parents with obesity prevention interventions. In the USA, approximately 11 million children under the age of 5 years attend some type of child care every week $^{(19)}$, making these locations ideal both for shaping the dietary habits of large numbers of children and for reaching their parents with educational messages. Yet, to date, few interventions delivered via childcare settings have focused comprehensively on encouraging young children to drink water and low- or non-fat milk in lieu of SSB and juice ${ }^{(20,21)}$.

To fill this gap, we developed and implemented a multilevel, multipronged intervention that encouraged young children to consume water and low- or non-fat unsweetened milk instead of juice and SSB. The present study aimed to evaluate the pilot intervention's impact on children's weight (overweight/obese status (primary outcome), BMI and BMI percentile) and beverage consumption, with a goal of determining the promise of the intervention and providing the data necessary to calculate sample size needs for larger trials. Based on previous studies of school-based water promotion interventions ${ }^{(9,22-25)}$, we predicted that the intervention would increase children's consumption of healthier beverages, reduce their consumption of less-healthy beverages and lower their likelihood of having an unhealthy weight.

\section{Methods}

\section{Participants}

Childcare centres and classrooms

We recruited a convenience sample of four childcare centres in northern California for this pilot study. Centres were eligible if they were in San Mateo County, CA; were licensed ${ }^{(26)}$; had enrolled at least ten children aged 2-5 years; had English- or Spanish-speaking staff; served primarily English- or Spanish-speaking families; and participated in the Child and Adult Care Food Program (a federal nutrition assistance programme providing funding for meals and snacks, and a marker for centres that serve lower-income children $\left.^{(27)}\right)$. With help from district-level administrators, we identified four centres in two cities (two centres per city) to participate in the study. We ensured that recruited centres within each city were similar in number of students per classroom and in the type of programme(s) offered (i.e. half$v$. full-day). Within each city, we randomly assigned one centre to the intervention group and the other to the control (delayed-intervention) group. A total of seven classrooms across the four centres participated: four classrooms in the intervention group and three classrooms in the control group.

\section{Parents and children}

At each centre, all eligible children and their parents were invited to participate. Children were eligible if they were 2-5 years old. Their parents were eligible if they spoke English or Spanish. Parents provided written informed consent for both their participation and their child's participation.

\section{Intervention}

We designed the intervention to encourage children to consume age-appropriate beverages consistent with expert recommendations ${ }^{(11)}$. The intervention promoted consumption of healthier beverages (i.e. water and unsweetened low- or non-fat milk) and recommended limiting consumption of less-healthy beverages (i.e. replacing juice with whole fruit and limiting SSB, including sweetened milk, to no more than one serving per week).

The 12-week intervention took place in spring 2014. We designed the intervention to operate at multiple levels of the Social Ecological Framework ${ }^{(28,29)}$ (Fig. 1). The intervention targeted children, parents and childcare centre staff and included three main components: (i) environmental changes; (ii) implementation of rules and policies; and (iii) educational activities. To enhance the feasibility, acceptability and effectiveness of the intervention, we assembled a community advisory board consisting of representatives from the county public health department, local childcare organizations (e.g. Head Start, the local childcare resource and referral agency and the school districts overseeing the participating childcare centres), childcare providers and parents with children of pre-school age. The community advisory board provided regular in-person and written feedback on intervention materials and implementation.

\section{Environmental changes}

Environmental changes focused on increasing children's access to water at childcare centres and at home. Prior to 


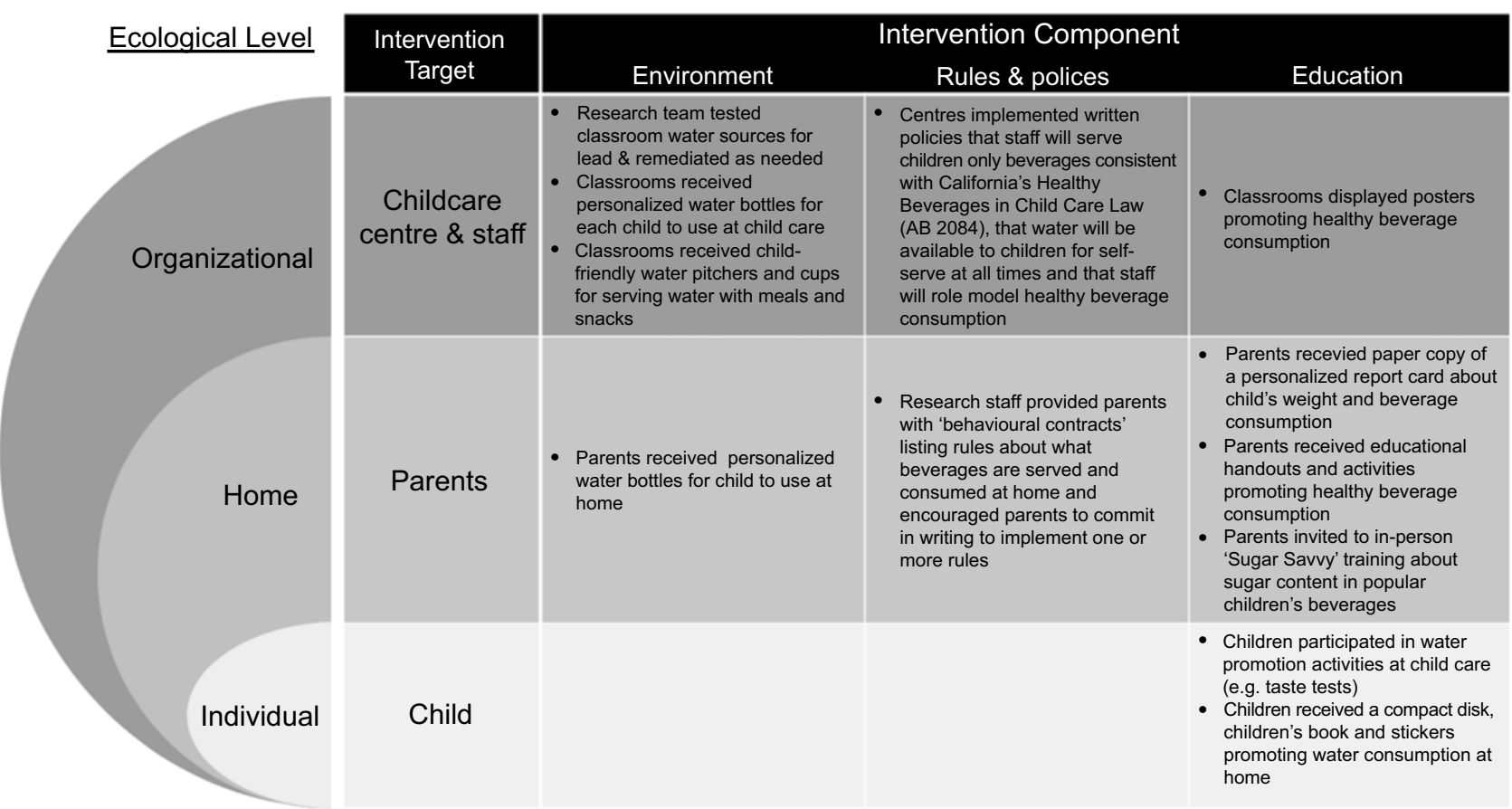

Fig. 1 Intervention activities used to promote children's healthy beverage consumption by social ecological level, intervention target and component

the intervention, the research team conducted water testing and remediation for lead in all intervention classrooms based on Environmental Protection Agency recommendations ${ }^{(30)}$. At baseline, no classrooms were serving water at all meals and snacks. To increase access to water during meal and snack times, the research team supplied classrooms with child-sized pitchers and cups so children could pour themselves water at meals and snacks. We also asked providers to serve children water at meals and snacks. We also observed that, at baseline, only one centre had water available for children to self-serve outside mealtimes. To increase children's access to water outside mealtimes, the research team provided all children with a child-sized reusable water bottle personalized with their name and photograph that they could use to serve themselves water throughout the day. Finally, to allow children to self-serve water outside childcare hours, we also provided each child with a second personalized water bottle to use at home.

\section{Policies}

In 2010, California passed AB 2084, the Healthy Beverages in Childcare Policy ${ }^{(31)}$. The policy, effective 1 January 2012, requires licensed childcare facilities in California to: (i) serve only milk that is low-fat (1\%) or non-fat to children over 2 years of age; (ii) refrain from providing juice or beverages with added sugar including sweetened milk; and (iii) provide clean and safe drinking-water at all times, including during meals and snacks. Despite AB 2084 having been in place for nearly 2 years at the time of the intervention, pre-intervention observations of classrooms indicated that only one centre was complying with the requirement to provide water at all times. Observations also revealed that some centres served juice or allowed parents to send juice or SSB with their children to child care and that no centres had integrated AB 2084 requirements into their written policies. These observations are consistent with previous research showing that there is often a delay between when policy makers pass new nutrition requirements and when childcare centres come into full compliance with these requirements ${ }^{(32)}$. To encourage implementation of $\mathrm{AB} 2084$, the study principal investigator met with centre directors and head teachers to explain the policy and to ask that centres comply with the new standards. Centre directors also incorporated rules about beverage access and consumption into their written staff handbooks or wellness policies using language provided by the research team.

The intervention also encouraged families to adopt rules to promote healthier beverage consumption at home. Parents received written 'behavioural contracts' listing rules about beverages they might consider adopting (e.g. limit children to no more than one serving of SSB per week; serve whole fruit instead of fruit juice). Parents were encouraged to commit in writing to implementing one or more of these rules. Parents who returned completed contracts were eligible for a raffle for water bottles and gift cards.

\section{Educational activities}

The intervention also included educational activities for both parents and children. Parents received personalized 
report cards describing their child's weight and beverage consumption (developed using children's baseline data and qualitative research on best practices for designing BMI report cards ${ }^{(33)}$ ), informational handouts (e.g. recipes for spa water) and interactive family activities (e.g. a worksheet for finding free water sources at the park). The research team delivered these written materials to parents via children's mailboxes at the childcare centre. Parents were also invited to attend an in-person training in which study staff described how to determine the amount of added sugar in popular children's beverages using the products' nutrition labels.

Children participated in a wide variety of engaging, ageappropriate educational activities while at child care, including spa-water taste tests (children sampled water infused with fruit or herbs), singing along to the 'Drink More Water' children's song developed specifically for the study ${ }^{(34)}$ and reading the children's book Potter the Otter: A Tale About Water ${ }^{(35)}$. Research assistants or childcare teachers facilitated these activities. To reinforce these lessons at home, children each received a compact disk with the 'Drink More Water' children's song, a copy of the Potter the Otter: A Tale About Water book and stickers promoting water consumption.

\section{Measures}

We assessed outcomes at baseline (late 2013) and immediately following the 12-week intervention period (spring of 2014). We examined children's weight status (overweight/ obese $v$. not), BMI percentile ${ }^{(36)}$, raw (absolute) $\mathrm{BMI}^{(36,37)}$ and children's at-home beverage consumption.

\section{Children's anthropometrics}

Trained research assistants measured children's anthropometrics using National Health and Nutrition Examination Survey (NHANES) protocols ${ }^{(38)}$, measuring height to the nearest $0 \cdot 1 \mathrm{~cm}$ using a portable stadiometer (Seca ${ }^{\circledR}$ North America; Chino, CA, USA) and weight to the nearest $0.01 \mathrm{~kg}$ using a digital scale (Tanita ${ }^{\circledR}$ Corporation; Arlington Heights, IL, USA). Measurements were collected at childcare centres during the day. All measurements were taken twice. If the two measurements differed by more than $1 \mathrm{~cm}$ (height) or $0 \cdot 1 \mathrm{~kg}$ (weight), a third was taken. We used the average of all measurements taken to compute BMI $\left(\mathrm{kg} / \mathrm{m}^{2}\right)$. We then calculated BMI percentile using the Centers for Disease Control and Prevention age- and sexspecific growth charts ${ }^{(39)}$ and classified children as overweight/obese if their BMI percentile was at or above the 85th percentile for their age and sex.

\section{Children's at-home beverage consumption}

We assessed children's at-home beverage consumption via parental report. Parents reported on their children's at-home beverage consumption for the past $24 \mathrm{~h}$ (excluding times while the child was at child care) using a questionnaire adapted from a previously validated instrument for assessing older children's beverage consumption ${ }^{(40)}$. Parents reported whether their child consumed beverages in twenty-two categories, including different types of milk, SSB (e.g. fruit drinks, Kool-Aid, sports drinks, sodas), $100 \%$ fruit juice, tap water and bottled water (see online supplementary material, Supplemental Table S2). For each beverage their child consumed, parents estimated the total amount the child drank in ounces (i.e. US fluid ounces; $1 \mathrm{US}$ fl. oz $=29.57 \mathrm{ml}$ ). Most parents self-administered a written version of the questionnaire; the research team verbally administered questionnaires to parents with lower literacy. To improve accuracy and completeness, research staff followed up with parents in-person or via phone regarding ambiguous or incomplete information.

We used parents' survey responses to calculate children's at-home beverage consumption, in ounces/d, of the following categories: (i) each of the healthier beverages promoted by the intervention (total water, tap water, bottled water, unsweetened low- or non-fat milk); (ii) each of the less-healthy beverages discouraged by the intervention (100\% juice, total SSB excluding sweetened milk, unsweetened high-fat milk, sweetened milk); (iii) all healthier beverages combined; and (iv) all less-healthy beverages combined. We did not assess children's beverage consumption while at child care.

\section{Demographics}

Baseline questionnaires asked parents to report their marital status, educational attainment, ethnicity (Hispanic/ Latino $v$. not), household income and number of household members. Parents also reported their child's sex and date of birth, which we used to calculate the child's exact age at the time of BMI measurements.

\section{Intervention fidelity}

To provide insight on the extent to which classrooms implemented the water availability component of the intervention, we conducted weekly, unannounced 'spot check' fidelity observations of intervention classrooms during meal or snack times. Trained observers recorded whether childcare staff served water to children during the meal or snack, as encouraged by the intervention. In addition, we conducted day-long observations immediately post-intervention using the Environmental and Policy Assessment and Observation (EPAO) instrument ${ }^{(41)}$ to assess compliance with various other aspects of the intervention (e.g. whether classrooms had water available for self-serve during outdoor playtime). Finally, we tracked the number of parents who returned a completed behavioural contract indicating they planned to implement one or more rule about beverages at home.

\section{Analysis}

To describe the sample, we calculated means, SD and proportions for child, parent and household characteristics. 
Table 1 Characteristics of 2- to 5-year-old children, parents and households by study group ( $n$ 154), two northern California cities, USA, 2013-2014

\begin{tabular}{|c|c|c|c|c|}
\hline \multirow[b]{2}{*}{ Characteristic } & \multicolumn{2}{|c|}{ Intervention ( $n$ 80) } & \multicolumn{2}{|c|}{ Control $(n 74)$} \\
\hline & Mean or \% & SD or $n$ & Mean or \% & SD or $n$ \\
\hline \multicolumn{5}{|l|}{ Children's characteristics } \\
\hline Age at baseline (years), mean and SD & $4 \cdot 10$ & 0.59 & $4 \cdot 32$ & 0.44 \\
\hline Male, $\%$ and $n$ & 45 & 36 & 46 & 34 \\
\hline Overweight/obese at baseline, $\%$ and $n$ & 43 & 34 & 39 & 29 \\
\hline \multicolumn{5}{|l|}{ Parent/household characteristics } \\
\hline Hispanic ethnicity, $\%$ and $n$ & 98 & 64 & 82 & 53 \\
\hline Education of high-school degree or less, $\%$ and $n$ & 66 & 49 & 54 & 34 \\
\hline Married, $\%$ and $n$ & 66 & 47 & 65 & 40 \\
\hline Annual household income $\leq \$$ US $30000, \%$ and $n$ & 67 & 51 & 67 & 43 \\
\hline No. of household members, mean and SD & 3.71 & 1.32 & 3.89 & 1.42 \\
\hline
\end{tabular}

Characteristics are presented by study group for qualitative comparison, thus $P$ values are not reported. Numbers may not sum to total sample size due to missing data on some characteristics.

To estimate intervention impact, we used generalized linear models with a difference-in-differences approach. For each outcome, we compared the change from baseline to follow-up (immediately post 12-week intervention) in the intervention group with the change over the same period in the control group. The primary outcome was children's overweight/obese status. Secondary outcomes were children's at-home consumption of: (i) each healthier beverage (i.e. total water, tap water, bottled water, unsweetened low- or non-fat milk); (ii) each less-healthy beverage (i.e. $100 \%$ juice, total SSB excluding sweetened milk, unsweetened high-fat milk, sweetened milk); (iii) all healthier beverages combined; and (iv) all less-healthy beverages combined. We also assessed BMI percentile and absolute BMI $\left(\mathrm{kg} / \mathrm{m}^{2}\right)$ as exploratory outcomes. Due to the pilot nature of the study, we did not conduct power analyses.

Analytic models controlled for child's age and sex (except for models assessing BMI percentile and weight status, which are already age- and sex-specific) and parent/household demographic characteristics (marital status, Hispanic ethnicity, income, educational attainment and household size). All models included indicators for time period (baseline $v$. follow-up), study group (intervention $v$. control), and an interaction between time period and study group.

Data were nested within children (repeated measures over time), classrooms and centres. Classroom-level intraclass correlation coefficients ranged from $<0.01$ to 0.07 and centre-level intraclass correlation coefficients ranged from $<0.01$ to 0.02 (Supplemental Table S3 in the online supplementary material presents intraclass correlation coefficients for all outcomes at the child, classroom and centre levels). To account for clustering, models clustered SE within children and included a set of indicator variables (i.e. fixed effects) for childcare classrooms. Inclusion of classroom fixed effects also accommodated and corrected for any potential pair effects resulting from having conducted randomization within cities. Missing data comprised $<15 \%$ of cases for all demographic variables. Analyses were conducted in the statistical software package Stata SE version 15.1.

To describe intervention fidelity, we calculated the proportion of meals/snacks at which childcare staff served water during the spot check fidelity observations. We also used EPAO observations to examine the number of intervention classrooms that complied with key intervention components (e.g. how many intervention classrooms served water at each meal). Finally, we calculated the proportion of parents who returned a behavioural contract to the research team indicating the rules about beverages they planned to implement.

Trial registration for the present study is available at ClinicalTrials.gov (NCT 03713840). The Committee on Human Research at the University of California San Francisco approved the study.

\section{Results}

All centres approached for the study agreed to participate. Two centres (four classrooms; eighty-seven children in total) were randomized to receive the healthy beverages intervention and two centres (three classrooms; seventy-seven children in total) were randomized to the control (delayedintervention) group (Fig. 2). Because the intervention was delivered via centres, all children (100\%) in randomized centres received the intervention. Most parents ( $n$ 161, 98\%) agreed to have their child's height and weight measured. Of the 161 children measured at baseline, seven ( $4 \%$ ) were lost to follow-up because the child was no longer enrolled at the facility, leaving 154 children with BMI data at both time points included in analyses of the primary outcome.

The sample was predominantly Hispanic/Latino and low-income, with two-thirds of parents reporting annual household income of \$US 30000 or less (Table 1). 


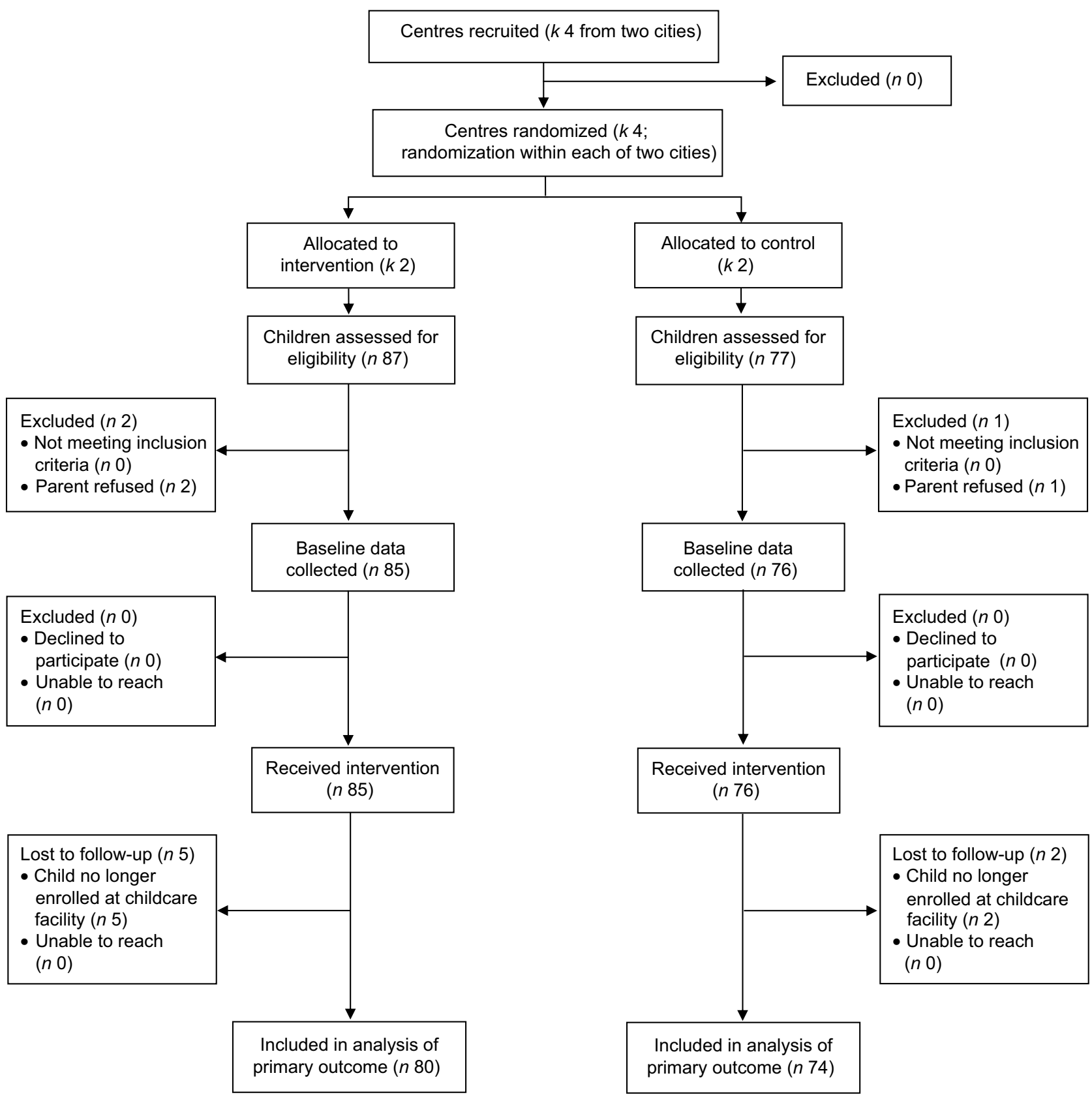

Fig. 2 Consolidated Standards of Reporting Trials (CONSORT) flow diagram showing recruitment of children and childcare centres for the present study ( $k$, number of childcare centres; $n$, number of children)

\section{Beverage consumption}

Results indicated that the intervention helped discourage children's at-home consumption of less-healthy beverages. Children in the intervention group showed larger reductions in consumption of all less-healthy beverages combined compared with children the control group (difference-in-differences (DD) $=-5.9$ ounces $/ \mathrm{d}$; $95 \% \mathrm{CI}-11 \cdot 2,-0.6(\mathrm{DD}=-174.5 \mathrm{ml} / \mathrm{d} ; 95 \% \mathrm{CI}-331 \cdot 2$, $-17 \cdot 7)$; Table 2, Fig. 3). The intervention also significantly reduced juice consumption ( $\mathrm{DD}=-1.9$ ounces/d; $95 \% \mathrm{CI}$ $-3 \cdot 5,-0 \cdot 2(\mathrm{DD}=-56 \cdot 2 \mathrm{ml} / \mathrm{d} ; 95 \% \mathrm{CI}-103 \cdot 5,-5 \cdot 9))$ and showed favourable but non-significant impacts on SSB consumption (DD $=-2.4$ ounces $/ \mathrm{d} ; 95 \% \mathrm{CI}-5.5,0.7$ (DD $=71.0 \mathrm{ml} / \mathrm{d} ; 95 \% \mathrm{CI}-162.6,20.7)$ ). Consumption of unsweetened high-fat milk decreased somewhat in the intervention group $(-2 \cdot 1$ ounces/d; $95 \%$ CI $-4 \cdot 3$, $0.03(-62.1 \mathrm{ml} / \mathrm{d} ; 95 \%$ CI $-127.2,0.9))$, compared with a decrease of 1.1 ounces/d $(32.5 \mathrm{ml} / \mathrm{d})$ in the control group (95\% CI -3.4, $1 \cdot 2$ (95\% CI -100.5, 35.5)), although the difference-in-differences between groups was not significant (DD $=-1.0$ ounces $/ \mathrm{d} ; \quad 95 \%$ CI $-3.9, \quad 1.9(\mathrm{DD}=-29.6 \mathrm{ml} / \mathrm{d} ; 95 \%$ CI $-115.3,56.2)$ ). Consumption of sweetened milk was stable over time in both groups. 
Table 2 Adjusted means and changes over time in 2- to 5-year-old children's beverage consumption, weight status and body mass by study group ( $n$ 154), two northern California cities, USA, 2013-2014

\begin{tabular}{|c|c|c|c|c|}
\hline & \multirow[b]{2}{*}{ Baseline } & \multirow[b]{2}{*}{ Follow-up } & \multicolumn{2}{|c|}{ Difference } \\
\hline & & & Point estimate & $95 \% \mathrm{Cl}$ \\
\hline \multicolumn{5}{|c|}{ Beverage consumption (ounces/d)* } \\
\hline \multicolumn{5}{|c|}{ All less-healthy beverages $\dagger$} \\
\hline Intervention group & $13 \cdot 1$ & $10 \cdot 8$ & $-2 \cdot 3$ & $-7 \cdot 2,2 \cdot 6$ \\
\hline Control group & $13 \cdot 9$ & $17 \cdot 5$ & $3 \cdot 6$ & $-0.8,7 \cdot 9$ \\
\hline Difference & & & $-5 \cdot 9$ & $-11 \cdot 2,-0.6$ \\
\hline \multicolumn{5}{|c|}{ All healthier beverages $\dagger$} \\
\hline Intervention group & $13 \cdot 8$ & $18 \cdot 8$ & 5.0 & $0.5,9.4$ \\
\hline Control group & $8 \cdot 3$ & $9 \cdot 8$ & 1.5 & $-2 \cdot 9,5 \cdot 9$ \\
\hline Difference & & & 3.5 & $-2 \cdot 6,9 \cdot 5$ \\
\hline \multicolumn{5}{|l|}{$100 \%$ Juice } \\
\hline Intervention group & $3 \cdot 4$ & 1.5 & -1.9 & $-3.4,-0.4$ \\
\hline Control group & $2 \cdot 1$ & $2 \cdot 0$ & -0.03 & $-1 \cdot 2,1 \cdot 1$ \\
\hline Difference & & & -1.9 & $-3.5,-0.2$ \\
\hline \multicolumn{5}{|c|}{ Total SSB excluding sweetened milk } \\
\hline Intervention group & 2.5 & $4 \cdot 3$ & $1 \cdot 8$ & $-1 \cdot 3,4 \cdot 8$ \\
\hline Control group & 0.5 & 4.7 & 4.2 & $1.4,7.0$ \\
\hline Difference & & & $-2 \cdot 4$ & $-5 \cdot 5,0 \cdot 7$ \\
\hline \multicolumn{5}{|c|}{ Unsweetened high-fat ( $2 \%$ or whole) milk } \\
\hline Intervention group & $4 \cdot 8$ & $2 \cdot 7$ & $-2 \cdot 1$ & $-4.3,0.03$ \\
\hline Control group & $9 \cdot 5$ & $8 \cdot 4$ & $-1 \cdot 1$ & $-3 \cdot 4,1 \cdot 2$ \\
\hline Difference & & & $-1 \cdot 0$ & $-3.9,1.9$ \\
\hline \multicolumn{5}{|l|}{ Sweetened milk } \\
\hline Intervention group & 1.2 & $1 \cdot 2$ & 0.1 & $-1 \cdot 2,1.4$ \\
\hline Control group & 1.0 & 1.0 & 0.02 & $-0.9,0.9$ \\
\hline Difference & & & $0 \cdot 1$ & $-1.4,1.5$ \\
\hline \multicolumn{5}{|l|}{ Total water† } \\
\hline Intervention group & $13 \cdot 7$ & $17 \cdot 6$ & 4.0 & $-0 \cdot 3,8 \cdot 2$ \\
\hline Control group & $6 \cdot 6$ & $8 \cdot 0$ & 1.4 & $-2 \cdot 9,5 \cdot 7$ \\
\hline Difference & & & $2 \cdot 6$ & $-3 \cdot 2,8 \cdot 4$ \\
\hline \multicolumn{5}{|l|}{ Tap water } \\
\hline Intervention group & $6 \cdot 5$ & $8 \cdot 6$ & $2 \cdot 1$ & $-1 \cdot 7,5 \cdot 9$ \\
\hline Control group & $1 \cdot 3$ & 0.8 & -0.5 & $-3 \cdot 5,2 \cdot 6$ \\
\hline Difference & & & 2.5 & $-2 \cdot 1,7 \cdot 2$ \\
\hline \multicolumn{5}{|l|}{ Bottled water } \\
\hline Intervention group & $7 \cdot 0$ & $8 \cdot 7$ & $1 \cdot 7$ & $-1 \cdot 8,5 \cdot 2$ \\
\hline Control group & 5.5 & $7 \cdot 0$ & $0 \cdot 6$ & $-1 \cdot 6,4 \cdot 7$ \\
\hline Difference & & & $0 \cdot 1$ & $-4 \cdot 0,4 \cdot 3$ \\
\hline \multicolumn{5}{|c|}{ Unsweetened low- or non-fat milk } \\
\hline Intervention group & 0.2 & $1 \cdot 2$ & 1.0 & $-0.5,2.5$ \\
\hline Control group & 1.7 & 1.8 & 0.1 & $-0 \cdot 9,1 \cdot 0$ \\
\hline Difference & & & 0.9 & $-0.7,2 \cdot 6$ \\
\hline \multicolumn{5}{|l|}{ Weight status and BMI } \\
\hline \multicolumn{5}{|c|}{ Overweight/obese status $\ddagger$ (\%) } \\
\hline Intervention group & 49 & 46 & -3 & $-10,3$ \\
\hline Control group & 36 & 38 & 3 & $-4,9$ \\
\hline Difference & & & -6 & $-15,3$ \\
\hline \multicolumn{5}{|l|}{ BMI percentile } \\
\hline Intervention group & $67 \cdot 6$ & $68 \cdot 3$ & 0.7 & $-1 \cdot 3,2 \cdot 6$ \\
\hline Control group & $78 \cdot 8$ & $78 \cdot 2$ & -0.5 & $-3 \cdot 6,2.5$ \\
\hline Difference & & & $1 \cdot 2$ & $-2.5,4.9$ \\
\hline \multicolumn{5}{|l|}{ Absolute BMI $\left(\mathrm{kg} / \mathrm{m}^{2}\right)$} \\
\hline Intervention group & $16 \cdot 2$ & $16 \cdot 4$ & 0.2 & $-0.1,0.5$ \\
\hline Control group & $17 \cdot 2$ & $17 \cdot 4$ & 0.1 & $-0.2,0.4$ \\
\hline Difference & & & 0.03 & $-0.2,0.3$ \\
\hline
\end{tabular}

SSB, sugar-sweetened beverage.

The table shows unstandardized coefficients from generalized linear regressions controlling sociodemographic characteristics and, for dietary outcomes and absolute BMI, child's age and sex. Models accounted for clustering by including classroom fixed effects and clustering SE within children. Classroom-level intraclass correlation coefficients ranged from $<0.01$ to 0.07 and centre-level intraclass correlation coefficients ranged from $<0.01$ to 0.02 (see online supplementary material, Supplemental Table 3 ). Coefficients and $\mathrm{Cl}$ in bold font are statistically significant at $P<0.05$.

*US fluid ounces; 1 US fl. oz = $29.57 \mathrm{ml}$.

†To estimate changes in larger beverage categories (i.e. total water, all healthier beverages and all less-healthy beverages), we first summed consumption across subcategories (e.g. tap and bottled water), then estimated the generalized linear regressions described above. Changes in consumption of the sub-categories do not perfectly sum to the change in consumption of the larger beverage categories due to adjustment for covariates.

$\ddagger$ Results for proportion overweight/obese are reported as predicted probabilities of being in the overweight/obese category and as marginal effects (i.e. percentage point change in likelihood of being in the overweight/obese category). 


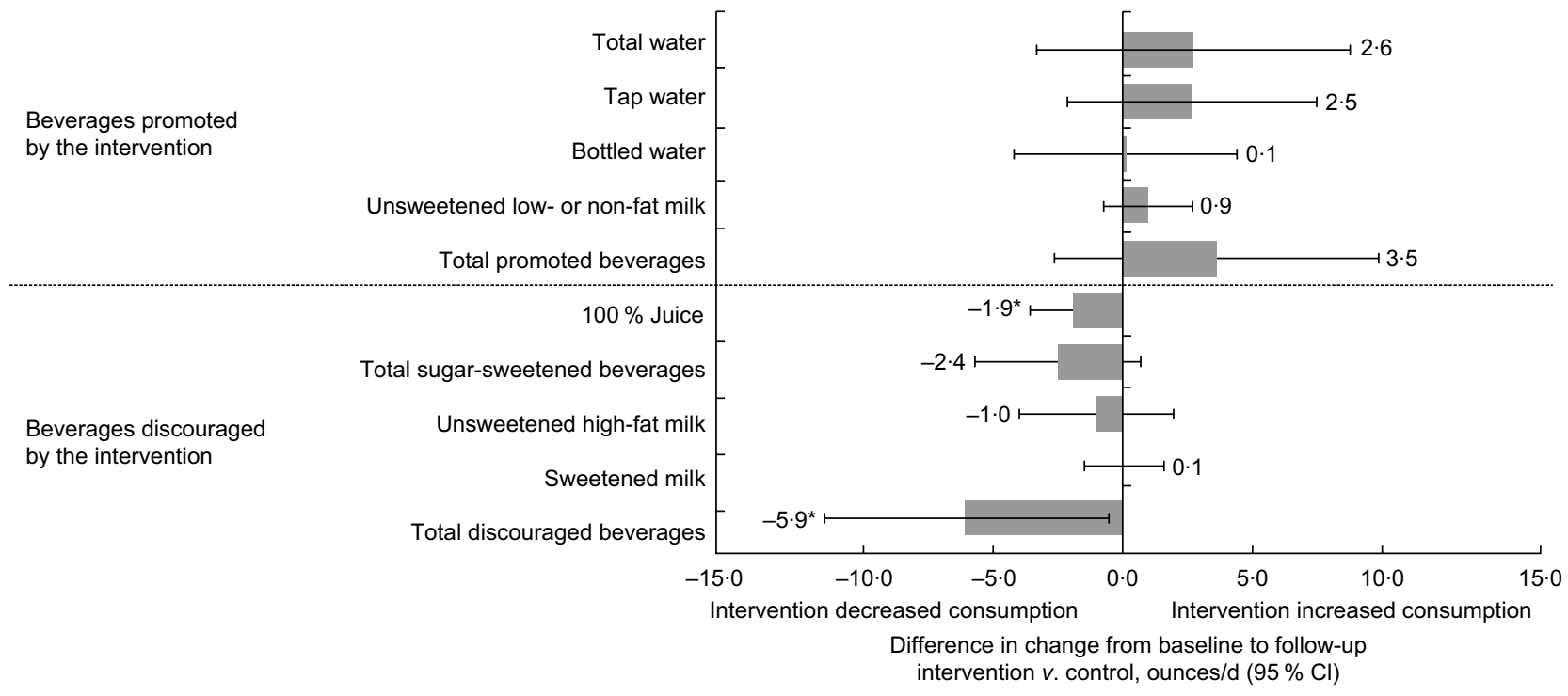

Fig. 3 Effects of the healthy beverages intervention on 2- to 5-year-old children's at-home consumption of eleven beverage categories ( $n$ 154), two northern California cities, USA, 2013-2014. Figure shows differences in change in consumption from baseline to follow-up ( ), with $95 \% \mathrm{Cl}$ represented by horizontal bars, comparing the healthy beverages intervention group with the control group, in ounces/d (i.e. US fluid ounces; 1 US fl. oz $=29.57 \mathrm{ml}$ ). Differences were estimated using generalized linear regressions, controlling for sociodemographic characteristics, child's age and child's sex, and accounting for clustering within children and classrooms. Changes in consumption of sub-categories may not sum to the changes in larger categories due to adjustment for covariates. ${ }^{\star} P<0.05$

Analyses also suggested that children in the intervention group had larger increases over time in their at-home consumption of healthier beverages than children in the control group. In total, the intervention group showed a larger increase in consumption of healthier beverages (+5.0 ounces $/ \mathrm{d} ; 95 \%$ CI $0.5,9.4(+147.9 \mathrm{ml} / \mathrm{d} ; 95 \% \mathrm{CI}$ $14.8,278.0))$ than the control group $(+1.5$ ounces/d; $95 \%$ CI $-2.9,5.9(+44.4 \mathrm{ml} / \mathrm{d} ; 95 \%$ CI $-85.8,174.5))$, although this difference-in-differences was not statistically significant $(\mathrm{DD}=+3.5$ ounces $/ \mathrm{d}$; $95 \% \mathrm{CI}-2 \cdot 6,9.5(\mathrm{DD}=+103.5 \mathrm{ml} / \mathrm{d}$; $95 \%$ CI $-76 \cdot 9,280 \cdot 9))$. Total water consumption increased somewhat more in the intervention group compared with the control group ( $\mathrm{DD}=+2.6$ ounces $/ \mathrm{d} ; 95 \% \mathrm{CI}-3.2$, 8.4 (DD $=+76.9 \mathrm{ml} / \mathrm{d} ; 95 \% \mathrm{CI}-94 \cdot 6,248.4)$ ), as did consumption of unsweetened low- and non-fat milk (DD $=+0.9$ ounces $/ \mathrm{d}$; $95 \% \mathrm{CI}-0 \cdot 7,2.6(\mathrm{DD}=+26.6 \mathrm{ml} / \mathrm{d} ; 95 \% \mathrm{CI}-20 \cdot 7,76 \cdot 9))$, although again these difference-in-differences did not reach statistical significance.

\section{Overweight/obese status and BMI}

At baseline, $43 \%$ of children in the intervention group and $39 \%$ of children in the control group were overweight/ obese (Table 1). After adjusting for covariates, the likelihood of being overweight/obese declined from baseline to follow-up by 3 percentage points (pp) in the intervention group and increased by $3 \mathrm{pp}$ in the control group (Table 2). Thus, the adjusted difference in changes over time between study groups was $-6 \mathrm{pp}$; this differencein-differences was not statistically significant $(95 \% \mathrm{CI}$ $-15,3)$. There were no differences in changes over time in BMI percentile ( $\mathrm{DD}=+1.2$ percentiles; $95 \% \mathrm{CI}-2.5$, 4.9) or absolute BMI (DD $=+0.03 \mathrm{~kg} / \mathrm{m}^{2} ; 95 \%$ CI $-0 \cdot 2,0 \cdot 3)$.

\section{Intervention fidelity}

Data triangulated across several sources suggested good intervention fidelity. First, childcare staff served children water during nearly all $(88 \%, n 37)$ of the forty-two spot check fidelity observations the research team conducted during meal and snack times. Second, post-intervention observations conducted using the EPAO instrument indicated good compliance with key components of the intervention. For example, of the three classrooms that served lunch, all served children water with the meal. Three out of the four classrooms that served an afternoon snack served children water with the snack. Additionally, in all four classrooms, children were prompted by teachers to consume water during meals and during playtime. Likewise, in all four classrooms, water was visible to children in the classroom, available for self-serve in the classroom and available for self-serve during outdoor playtime. None of the observed intervention classrooms served juice at any meal or snack, and none served any milk other than unsweetened low- or non-fat milk. One area where centres could have improved was serving water with breakfast: of the three classrooms that served breakfast, only one served children water with the meal. Finally, data also suggested parents were engaged with the intervention. More than half of parents ( $58 \%$ of the eighty-one parents 
participating in the intervention) returned signed behavioural contracts to the research team indicating which beverage rules they planned to implement at home.

\section{Discussion}

We found that compared with a control group, children exposed to a focused healthy beverages intervention significantly decreased their consumption of less-healthy beverages. Children in the healthy beverages intervention also increased their consumption of healthier beverages compared with the control group, although these relative improvements were not statistically significant. Effects on overweight/obese status were favourable but also nonsignificant. Beverage consumption is a major contributor to childhood obesity ${ }^{(6,7)}$ and early childhood is increasingly recognized as a critical period for establishing both healthy dietary behaviours and a healthy body weight ${ }^{(42)}$. The present intervention is among the first delivered via childcare centres to focus exclusively and comprehensively on encouraging children to consume water and unsweetened low- or non-fat milk in place of SSB and $100 \%$ juice ${ }^{(20,21)}$.

The intervention showed promise at increasing consumption of both water and unsweetened low- or non-fat milk, the beverages promoted by the intervention. Children in the intervention group increased their at-home water consumption by 2.6 ounces $/ \mathrm{d}(76.9 \mathrm{ml} / \mathrm{d})$ more than the control group. In addition to helping limit excess weight gain ${ }^{(9,10)}$, this increase in water intake could potentially reduce children's risk of inadequate hydration ${ }^{(43)}$ and improve their $\operatorname{cog}^{-}$ nitive functioning ${ }^{(44-47)}$. Children in the intervention group also increased their at-home consumption of unsweetened low- or non-fat milk by about 1 ounce $/ \mathrm{d}(30 \mathrm{ml} / \mathrm{d})$ relative to the control group. Consumption of unsweetened lowor non-fat milk helps children meet recommended levels of calcium, potassium and vitamin D intake while avoiding the excess sugar, saturated fat and energy found in highfat and sweetened milk ${ }^{(48)}$.

The intervention also helped children limit their at-home consumption of the less-healthy beverages discouraged by the intervention. The intervention significantly reduced juice consumption and was also associated with a relatively large although non-significant reduction in SSB consumption. Reduced consumption of juice and SSB could help children maintain a healthier weight ${ }^{(6,7)}$ and may also reduce their risk of dental caries ${ }^{(49)}$, diabetes ${ }^{(50)}$, hyperlipidaemia and fatty liver disease ${ }^{(51)}$. Consumption of high-fat milk also decreased in the intervention group relative to the control group, although not significantly. In total, the intervention significantly reduced children's at-home consumption of all less-healthy beverages combined by nearly 6 ounces/d $(177 \mathrm{ml} / \mathrm{d})$ relative to the control group.

If sustained, this observed reduction in consumption of less-healthy beverages could help children maintain healthier weight. To contextualize the potential benefits of these changes in beverage intake, we used the US Department of Agriculture's online nutrition database Supertracker ${ }^{(52)}$ to translate intervention impact on volume of beverages consumed into impact on energy and added sugar consumed (see online supplementary material, Supplemental Table S4). We summed intervention impacts across all beverage categories, accounting for both decreases in beverages like SSB and juice as well as increases in beverages like unsweetened low- or non-fat milk. Assuming no other dietary changes, the intervention was estimated to help children avert more than $251 \mathrm{~kJ} / \mathrm{d}$ $(60 \mathrm{kcal} / \mathrm{d})$, well above the amount needed to achieve Healthy People 2020 goals for obesity prevalence among young children ${ }^{(53)}$. The observed changes in beverage consumption could also result in children consuming nearly six fewer grams of added sugar per day, a notable finding given that 2- to 5-year-olds consume more than twice the daily recommended amount of added sugar ${ }^{(51)}$.

Despite these encouraging changes in children's beverage consumption habits, we did not observe statistically significant intervention effects on overweight/obese status, likely due to the study's short duration and small sample size. One systematic review of childhood obesity prevention interventions suggested that follow-up periods of 7.5 months or longer may be needed to demonstrate changes in weight status ${ }^{(54)}$. Future studies should follow children for a longer period to determine whether the improvements seen in beverage intake are sustained and whether such changes ultimately impact children's weight.

We note several limitations. First, while trained staff objectively measured height and weight, dietary behaviours were self-reported. Second, because our objective was to determine the promise of this intervention, we employed a relatively short follow-up period and it is not clear if the observed changes in beverage consumption would be sustained over time. We also measured children's at-home beverage consumption only and did not assess their behaviours while at child care, meaning that we likely underestimated children's total beverage consumption, particularly for children attending full-day childcare programmes. We also did not assess food intake and cannot determine whether children compensated for any reductions in energy intake from beverages by increasing their energy intake from foods. Additionally, we recruited a relatively small sample of mostly lowincome, Hispanic families from a convenience sample of four childcare centres in a limited geographical area and our findings may not generalize to samples with different sociodemographic characteristics or in different geographic areas. Future studies should examine multipronged beverage-focused interventions in other populations, with longer follow-up periods and with larger samples. Additional research could also help determine whether parents and childcare centres can maintain the intervention's environmental and policy changes in the absence of a research study ${ }^{(55)}$. 
There are several unique strengths to the present pilot study. We designed a theory-informed intervention that simultaneously targeted factors at the child, home and organizational social ecological levels. The multipronged intervention included a variety of creative strategies to address these multiple levels, including hands-on, engaging educational activities for both children and parents; meaningful environmental changes to promote children's access to water and reduce their access to juice and SSB, both while at home and at child care; and policy and rule changes across the two contexts. We also conducted regular in-person spot check fidelity observations to ensure childcare centres' compliance with the intervention, finding that childcare staff were largely implementing the intervention as intended. Finally, this is among the first interventions focused intensively on improving young children's beverage consumption as an obesity prevention strategy. Many effective obesity prevention interventions for young children have targeted both nutrition and physical activity simultaneously ${ }^{(56-65)}$. The present study suggests that focusing more narrowly on beverages may provide a simple yet effective means of promoting healthy weight in young children.

\section{Conclusions}

We developed and evaluated a beverage-focused intervention that targeted children, parents and childcare centre staff using a variety of strategies. Our results suggest that such interventions have promise for improving children's at-home beverage consumption and weight outcomes. Future studies should examine children over longer periods, include a larger number of childcare centres serving diverse populations, and assess both food and beverage intake at childcare centres as well as at home.

\section{Acknowledgements}

Acknowledgements: The authors thank Keren Eyal, Maria Martin, Céline Stamets, Kiah Thorne and Meagan Treviño for assistance with data collection and Emily Altman for assistance with data management. Financial support: This study was supported by the National Institutes of Health (grant number K23 HD067305 to A.I.P.). General support and training support for A.H.G. were provided by the Carolina Population Center (grant numbers P2C HD050924 and T32 HD007168). A.A.H. was supported through the Johns Hopkins Center for a Livable Future Lerner Fellowship. C.D.B. was supported in part by grants from the Maternal and Child Health Bureau, Health Resources and Services Administration, US Department of Health and Human Services (grant numbers U45MC27709 and UA6MC27378) to the Division of Adolescent and Young Adult Medicine, Department of Pediatrics, University of California San Francisco. The funders had no role in the study design; the collection, analysis or interpretation of the data; the writing of the report; or the decision to submit the manuscript for publication. Conflict of interest: None. Authorship: A.H.G. coordinated data collection, analysed the data, drafted the initial manuscript, and reviewed and revised the manuscript. M.D.C., A.A. and C.D.B. provided critical intellectual input on study design, data collection instruments, data analysis and interpretation, and manuscript development and revisions. A.A.H. assisted with analyses, helped interpret the data and critically reviewed the manuscript. C.E.M. supervised data analysis and interpretation and critically reviewed the manuscript. A.I.P. conceptualized and designed the study, supervised all aspects of the study and critically reviewed the manuscript for important intellectual content. All authors reviewed and approved the final manuscript. Ethics of human subject participation: This study was conducted according to the guidelines laid down in the Declaration of Helsinki and all procedures involving human subjects were approved by the Committee on Human Research at the University of California San Francisco. Written informed consent was obtained from all subjects.

\section{Supplementary material}

To view supplementary material for this article, please visit https://doi.org/10.1017/S1368980019001629

Author ORCID. (1) Anna H Grummon, 0000-00028705-038X.

\section{References}

1. Skinner AC, Ravanbakht SN, Skelton JA et al. (2018) Prevalence of obesity and severe obesity in US children, 1999-2016. Pediatrics 141, e20173459.

2. Must A \& Strauss RS (1999) Risks and consequences of childhood and adolescent obesity. Int J Obes Relat Metab Disord 23, Suppl. 2, S2-S11.

3. Reilly JJ \& Kelly J (2011) Long-term impact of overweight and obesity in childhood and adolescence on morbidity and premature mortality in adulthood: systematic review. Int J Obes (Lond) 35, 891-898.

4. Ebbeling CB, Feldman HA, Chomitz VR et al. (2012) A randomized trial of sugar-sweetened beverages and adolescent body weight. $N$ Engl J Med 367, 1407-1416.

5. de Ruyter JC, Olthof MR, Seidell JC et al. (2012) A trial of sugar-free or sugar-sweetened beverages and body weight in children. $N$ Engl J Med 367, 1397-1406.

6. Malik V, Pan A, Willett WC et al. (2013) Sugar-sweetened beverages and weight gain in children and adults: a systematic review and meta-analysis. Am J Clin Nutr 98, 1084-1102.

7. Auerbach BJ, Wolf FM, Hikida A et al. (2017) Fruit juice and change in BMI: a meta-analysis. Pediatrics 139, e20162454.

8. Sonneville KR, Long MW, Rifas-Shiman SL. et al. (2014) Juice and water intake in infancy and later beverage intake and adiposity: could juice be a gateway drink? Obesity (Silver Spring) 23, 170-176. 
9. Muckelbauer R, Libuda L, Clausen K et al. (2009) Promotion and provision of drinking water in schools for overweight prevention: randomized, controlled cluster trial. Pediatrics 123, e661-e667.

10. Wang YC, Ludwig DS, Sonneville K et al. (2009) Impact of change in sweetened caloric beverage consumption on energy intake among children and adolescents. Arch Pediatr Adolesc Med 163, 336-343.

11. Story M (2013) Recommendations for Healthier Beverages. Princeton, NJ: Robert Wood Johnson Foundation.

12. National Academies of Sciences, Engineering, and Medicine (2017) Strategies to Limit Sugar-Sweetened Beverage Consumption in Young Children: Proceedings of a Workshop. Washington, DC: National Academies Press.

13. Heyman MB \& Abrams SA (2017) Fruit juice in infants, children, and adolescents: current recommendations. Pediatrics 136, e20170967.

14. Patel AI, Moghadam SD, Freedman M et al. (2018) The association of flavored milk consumption with milk and energy intake, and obesity: a systematic review. Prev Med 111, 151-162.

15. Briefel RR, Wilson A, Cabili C et al. (2013) Reducing calories and added sugars by improving children's beverage choices. J Acad Nutr Diet 113, 269-275.

16. Bleich SN, Vercammen KA, Koma JW et al. (2018) Trends in beverage consumption among children and adults, 2003-2014. Obesity (Silver Spring) 26, 432-441.

17. Kit BK, Fakhouri TH, Park S et al. (2013) Trends in sugar-sweetened beverage consumption among youth and adults in the United States: 1999-2010. Am J Clin Nutr 98, 180-188.

18. Kay MC, Welker EB, Jacquier EF et al. (2018) Beverage consumption patterns among infants and young children (0-47.9 months): data from the Feeding Infants and Toddlers Study, 2016. Nutrients 10, 825.

19. ChildCare Aware of America (2018) About child care. http:// usa.childcareaware.org/families-programs/about-child-care/ (accessed June 2019).

20. Cradock A, Poole M, Agnew K et al. (2019) A systematic review of strategies to increase drinking water access and consumption among 0- to 5-year olds. Obes Rev. Published online: 29 June 2019. doi: 10.1111/obr.12833.

21. Vercammen K, Frelier J, Lowery C et al. (2018) A systematic review of strategies to reduce sugar-sweetened beverage consumption among 0 -year to 5-year olds. Obes Rev 19, 1504-1524.

22. Kenney EL, Gortmaker SL, Carter JE et al. (2015) Grab a cup, fill it up! An intervention to promote the convenience of drinking water and increase student water consumption during school lunch. Am J Public Health 105, 1777-1783.

23. Elbel B, Mijanovich T, Abrams C et al. (2015) A water availability intervention in New York City public schools: influence on youths' water and milk behaviors. Am J Public Health 105, 365-372.

24. Patel AI, Grummon AH, Hampton KE et al. (2016) A trial of the efficacy and cost of water delivery systems in San Francisco Bay Area middle schools, 2013. Prev Chronic Dis 13, E88.

25. Schwartz AE, Leardo M, Aneja S et al. (2016) Effect of a school-based water intervention on child body mass index and obesity. JAMA Pediatr 170, 220-226.

26. California Department of Social Services (2018) Child care licensing. http://www.cdss.ca.gov/inforesources/ Child-Care-Licensing (accessed July 2017).

27. Yaktine A \& Moats S (2011) Child and Adult Care Food Program: Aligning Dietary Guidance for All. Washington, DC: Food and Nutrition Board, Institute of Medicine of the National Academies.

28. Story M, Kaphingst KM, Robinson-O'Brien R et al. (2008) Creating healthy food and eating environments: policy and environmental approaches. Annu Rev Public Health 29, 253-272.

29. Sallis J, Owen N \& Fisher EB (2008) Ecological models of health behavior. In Health Behavior and Health Education: Theory, Research, and Practice, 4th ed., pp. 465-485. San Francisco, CA: Jossey-Bass.

30. Environmental Protection Agency (2017) Drinking water requirements for states and public water systems | Lead and copper rule. https://www.epa.gov/dwreginfo/leadand-copper-rule (accessed May 2018).

31. Brownley J (2010) Child day care facilities: nutrition. Health and Safety Code, vol. 1596.808. http://www.leginfo.ca.gov/ pub/09-10/bill/asm/ab_2051-2100/ab_2084_bill_20100930_ chaptered.html (accessed July 2019).

32. Lee DL, Gurzo K, Yoshida S et al. (2018) Compliance with the New 2017 Child and Adult Care Food Program Standards for Infants and Children before Implementation. Child Obes 14, 393-402.

33. Thompson H, Linchey J \& Madsen K (2015) Critical elements of a school report to parents on body mass index. Prev Chronic Dis 12, E136.

34. Zamenes A (2014) Drink More Water! https://www.youtube. $\mathrm{com} /$ watch? $\mathrm{v}=$ QrWquDo7TzE (accessed March 2019).

35. Singh S (2012) Potter the Otter: A Tale About Water. USA: FIRST 5 Santa Clara County.

36. Cole TJ, Faith MS, Pietrobelli A et al. (2005) What is the best measure of adiposity change in growing children: BMI, BMI\%, BMI z-score or BMI centile? Eur J Clin Nutr 59, 419-425.

37. Berkey CS \& Colditz GA (2007) Adiposity in adolescents: change in actual BMI works better than change in BMI z-score for longitudinal studies. Ann Epidemiol 17, $44-50$.

38. Centers for Disease Control and Prevention (2007) National Health and Nutrition Examination Survey (NHANES) Anthropometry Manual. Atlanta, GA: CDC.

39. Centers for Disease Control and Prevention, National Center for Health Statistics (2000) CDC Growth Charts: United States. Atlanta, GA: CDC.

40. Grummon AH, Hampton KE, Hecht A et al. (2017) Validation of a brief questionnaire against direct observation to assess adolescents' school lunchtime beverage consumption. J Nutr Educ Behav 49, 847-851.e1.

41. Ward D, Hales D, Haverly K et al. (2008) An instrument to assess the obesogenic environment of child care centers. Am J Health Behav 32, 380-386.

42. Birch L, Parker L \& Burns A (editors) (2011) Early Childhood Obesity Prevention Policies. Washington, DC: National Academies Press.

43. Kenney EL, Long MW, Cradock AL et al. (2015) Prevalence of inadequate hydration among US children and disparities by gender and race/ethnicity: National Health and Nutrition Examination Survey, 2009-2012. Am J Public Health 105, e113-e118.

44. Benton D \& Burgess N (2009) The effect of the consumption of water on the memory and attention of children. Appetite 53, 143-146.

45. D'Anci KE, Constant F \& Rosenberg IH (2006) Hydration and cognitive function in children. Nutr Rev 64, 457-464.

46. Masento NA, Golightly M, Field DT et al. (2014) Effects of hydration status on cognitive performance and mood. Br J Nutr 111, 1841-1852.

47. Edmonds CJ \& Jeffes B (2009) Does having a drink help you think? 6-7-year-old children show improvements in cognitive performance from baseline to test after having a drink of water. Appetite 53, 469-472.

48. US Department of Health and Human Services \& US Department of Agriculture (2015) Dietary Guidelines for Americans 2015-2020, 8th ed. Washington, DC: USDA and HHS. 
49. Marshall TA, Levy SM, Broffitt B et al. (2003) Dental caries and beverage consumption in young children. Pediatrics 112, e184-e191.

50. Malik VS, Popkin BM, Bray GA et al. (2010) Sugar-sweetened beverages and risk of metabolic syndrome and type 2 diabetes: a meta-analysis. Diabetes Care 33, 2477-2483.

51. Vos MB, Kaar JL, Welsh JA et al. (2017) Added sugars and cardiovascular disease risk in children: a scientific statement from the American Heart Association. Circulation 135, e1017-e1034.

52. US Department of Agriculture (2018) Supertracker | FoodA-Pedia. https://www.supertracker.usda.gov/foodapedia. aspx? CatgoryID $=-1 \&$ FoodDescription=soda (accessed June 2018).

53. Wang YC, Hsiao A, Orleans CT et al. (2013) The caloric calculator: average caloric impact of childhood obesity interventions. Am J Prev Med 45, e3-e13.

54. Bluford DAA, Sherry B \& Scanlon KS (2007) Interventions to prevent or treat obesity in preschool children: a review of evaluated programs. Obesity (Silver Spring) 15, 1356-1372.

55. Glasgow RE, Vogt TM \& Boles SM (1999) Evaluating the public health impact of health promotion interventions: the RE-AIM framework. Am J Public Health 89, 1322-1327.

56. Alkon A, Crowley AA, Neelon SEB et al. (2014) Nutrition and physical activity randomized control trial in child care centers improves knowledge, policies, and children's body mass index. BMC Public Health 14, 215.

57. Fitzgibbon ML, Stolley MR, Schiffer L et al. (2005) Two-year follow-up results for Hip-Hop to Health Jr.: a randomized controlled trial for overweight prevention in preschool minority children. J Pediatr 146, 618-625.
58. Eliakim A, Nemet D, Balakirski Y et al. (2007) The effects of nutritional-physical activity school-based intervention on fatness and fitness in preschool children. $J$ Pediatr Endocrinol Metab 20, 711-718.

59. Puder JJ, Marques-Vidal P, Schindler C et al. (2011) Effect of multidimensional lifestyle intervention on fitness and adiposity in predominantly migrant preschool children (Ballabeina): cluster randomised controlled trial. BMJ 343, d6195.

60. Zask A, Adams JK, Brooks LO et al. (2012) Tooty fruity vegie: an obesity prevention intervention evaluation in Australian preschools. Health Promot J Aust 23, 10-15.

61. De Coen V, De Bourdeaudhuij I, Vereecken C et al. (2012) Effects of a 2-year healthy eating and physical activity intervention for 3-6-year-olds in communities of high and low socio-economic status: the POP (Prevention of Overweight among Pre-school and school children) project. Public Health Nutr 15, 1737-1745.

62. Herman A, Nelson BB, Teutsch C et al. (2012) 'Eat healthy, stay active!': a coordinated intervention to improve nutrition and physical activity among head start parents, staff, and children. Am J Health Promot 27, e27-e36.

63. Yin Z, Parra-Medina D, Cordova A et al. (2012) Míranos! Look at us, we are healthy! An environmental approach to early childhood obesity prevention. Child Obes 8, 429-439.

64. Zhou Z, Ren H, Yin Z et al. (2014) A policy-driven multifaceted approach for early childhood physical fitness promotion: impacts on body composition and physical fitness in young Chinese children. BMC Pediatrics 14, 118.

65. Salazar G, Vasquez F, Concha F et al. (2014) Pilot nutrition and physical activity intervention for preschool children attending daycare centres (JUNJI): primary and secondary outcomes. Nutr Hosp 29, 1004-1012. 